\title{
Article \\ Complications Following Non-Surgical Aesthetic Treatments in HIV+ Patients Receiving Antiretroviral Therapy: A 12-Years Experience
}

\author{
Fabrizio Chirico ${ }^{1, *}$, Giuseppe Mario Rauso ${ }^{2}$, Romolo Fragola ${ }^{3}$, Giorgio Lo Giudice ${ }^{3}\left(\mathbb{D}\right.$, Ludovico Pinto $^{3}$, \\ Nadia De Falco ${ }^{4}$, Angelo Cosenza ${ }^{4}$, Luigi Rugge ${ }^{1}$, Nicola Sgaramella ${ }^{5}$ and Gianpaolo Tartaro ${ }^{3}$ \\ 1 Private Practice, 80136 Naples, Italy; luigirugge@gmail.com \\ 2 Private Practice, 81055 Santa Maria Capua Vetere, Italy; centroapollonia@pec.it \\ 3 Maxillofacial Surgery Unit, Multidisciplinary Department of Medical-Surgical and Dental Specialities, \\ University of Campania “Luigi Vanvitelli”, 80138 Naples, Italy; romolofragola@gmail.com (R.F.); \\ Giorgio.logiudice@gmail.com (G.L.G.); ludovicopinto01@gmail.com (L.P.); \\ gianpaolo.tartaro@unicampania.it (G.T.) \\ 4 General Surgery Unit, Department of Advanced Medical and Surgical Sciences, \\ University of Campania "Luigi Vanvitelli", Piazza Miraglia, 80138 Naples, Italy; \\ nadia.defalco@outlook.it (N.D.F.); angelo.cosenza@unicampania.it (A.C.) \\ 5 Private Practice, 70125 Bari, Italy; sgaramellanicola12@gmail.com \\ * Correspondence: fabriziochirico@hotmail.com; Tel.: +39-3283678855
}

\section{check for} updates

Citation: Chirico, F.; Rauso, G.M.; Fragola, R.; Lo Giudice, G.; Pinto, L.; De Falco, N.; Cosenza, A.; Rugge, L.; Sgaramella, N.; Tartaro, G.

Complications Following

Non-Surgical Aesthetic Treatments in HIV+ Patients Receiving Antiretroviral Therapy: A 12-Years Experience. Appl. Sci. 2021, 11, 4059. https://doi.org/10.3390/app11094059

Academic Editor: Antonio Scarano

Received: 13 April 2021

Accepted: 27 April 2021

Published: 29 April 2021

Publisher's Note: MDPI stays neutral with regard to jurisdictional claims in published maps and institutional affiliations.

Copyright: (c) 2021 by the authors. Licensee MDPI, Basel, Switzerland. This article is an open access article distributed under the terms and conditions of the Creative Commons Attribution (CC BY) license (https:/ / creativecommons.org/licenses/by/ $4.0 /)$.

\begin{abstract}
Since the advent of HIV antiretroviral therapies at the end of the 20th century, the morbidity and mortality rates associated with HIV infection have decreased dramatically. Unfortunately, these benefits are associated with substantial morphologic changes in the body, such as abnormal fat distribution with peripheral lipohypertrophy and facial lipoatrophy. Facial wasting is considered the major stigma for HIV-infected people and may result in reduced antiretroviral adherence. Patients suffering from the stigmata of HIV infection can benefit from non-surgical aesthetic treatments performed with fillers or lipolytic agents that provide a quick and reliable service for facial rejuvenation, with high patient satisfaction and a low risk of complications. In the present paper, a retrospective analysis of complications following non-surgical aesthetic treatments (calcium hydroxyapatite-based filler, hyaluronic acid filler, polyacrylamide hydrogel filler and dehoxycholic acid injections), in a cohort of 116 consecutive HIV+ patients, treated over a period of 12 years, was performed. With the exception of the tardive swelling reported after calcium hydroxyapatite injections, complications were recorded just after polyacrylamide hydrogel treatment as small, palpable, nonvisible nodules or aseptic abscess. Our experience is consistent with those already published in the literature and the complication rate seems to be comparable to non-infected patients.
\end{abstract}

Keywords: complication; filler; permanent filler; calcium hydroxyapatite; facial wasting syndrome; facial lipoatropy; antiretroviral therapy; dehoxycholic acid; HIV; minimally invasive technique; surgical drainage

\section{Introduction}

Since the advent of HIV antiretroviral therapies at the end of the 20th century, the morbidity and mortality rates associated with HIV infection have decreased dramatically [1,2]. Unfortunately, these benefits are associated with substantial morphologic changes in the body, such as abnormal fat distribution with peripheral lipohypertrophy (gynecomastia, buffalo hump, etc.) and facial wasting, as well as potential systemic adverse effects. Facial lipoatrophy, defined as flattening or indentation of normally convex facial contours, is the major stigma for human immunodeficiency virus-infected people [3,4]. It can have dramatic effects on their self-esteem and socialization, and it may result in reduced antiretroviral adherence [5]. During the years, an increasing number of HIV patients receiving highly 
active antiretroviral therapy had medical consultations requesting an option to correct their resulting deformities, such as buffalo hump and facial wasting [6].

Surgical and non-surgical strategies have been introduced to restore facial features in the patient population. The use of peripheral hypertrophied fat to restore the facial lipoatrophy with lipofilling theoretically seems to be the best option. In fact, during the same operation not only can facial wasting be treated, but body contouring procedures can also be performed $[7,8]$. On the other hand, not all patients present both facial lipoatrophy and body lipohypetrophy. Moreover, as for the procedures performed only for cosmetic purposes, not all patients are prone to a surgical approach $[9,10]$. The request for nonsurgical aesthetic procedures has increased during the last 20 years. Statistics released by the American Society for Aesthetic Plastic Surgery in 2016 showed a dramatic increase in surgical and non-surgical cosmetic procedures throughout the preceding 20 years [11]. The number of plastic surgery procedures doubled from 1995 to 2015 and the quantity of non-surgical cosmetic procedures increased by 12 -fold, which demonstrates that an increasing number of subjects are seeking cosmetic improvements and that non-surgical procedures are preferred over surgical interventions [10].

Aesthetic procedures to improve facial wrinkles and folds have been widely described in the literature: filler injection has been among the most frequently used treatments in facial recontouring, restoring a smoother and more youthful looking appearance [12]. Hyaluronic acid (HA) filler is an attractive substance to be used as filler, which is because of its features such as the ability to bind to large amounts of water and the natural presence of HA in the skin. It is synthesized on cell membrane of fibroblasts and keratinocytes, and also plays an important role in skin hydration facilitating cellular movement in inflammation and wound healing and its decrease is associated with skin aging [12,13]. HA injection was the second most popular nonsurgical cosmetic with a 60\% increase from 2014 to 2018 and this could be explained by its affordability, minimal downtime, immediate results, minimal invasiveness and good safety profile, deriving from the feature that HA can be dissolved easily with hyaluronidase in case of complications [14]. Deep injections may yield an enduring result: Mashiko demonstrated that semi-permanent volumizing effects can be achieved if the target area has an underlying bony floor, hypothesizing that periosteal stem cells, activated by HA, potentiate the volumizing effect [15]. Calcium hydroxylapatite (CaHA)filler is an injectable, biocompatible, nontoxic, non-irritating and nonantigenic material composed of synthetic calcium hydroxylapatite microspheres suspended in an aqueous carrier gel [16]. In 2006, its use was approved by Food and Drug Administration for the restoration and correction of the signs of lipoatrophy in individuals with HIV. After injection, the carrier gel is gradually absorbed and the CaHA particles remain. A local fibroblastic response at the site results in collagen matrix encapsulation of the CaHA particles resulting in a long-lasting implant with characteristics similar to those of adjacent tissue. Even if calcium hydroxylapatite filler effectively ameliorates facial appearance of patients, the injection could be painful as in case of injection of a large volume of product to correct HIV-related facial lipoatrophy. However, mixing it with local anesthetic and adrenaline can reduce pain during injection and the percentage of ecchymosis. Polyacrylamide hydrogel is a permanent filler made up of a homogenous transparent gel of $2.5 \%$ cross-linked polyacrylamide and $97.5 \%$ sterile water. The volume of the implant is given by water not from a solid product. The body accepts the gel and forms a thin membrane around the implant that helps to keep it in place. As the gel is very elastic, it moves with all facial expression [17]. The use of permanent fillers is still debated: proponents of non-permanent fillers stress the importance of how aging will continually change the overlying structure of a person's face. However, patient affected by facial wasting ask for a permanent solution more often. It has demonstrated efficacy from its indications in facial recontouring as lip augmentation, smoothing of nasolabial folds, filling depressed mouth corners and perioral wrinkles [18]. However, it is mandatory to discuss with the patient before the treatment about complications, that include hematomas, edema, alteration of skin pigment, itching or dramatic product infection that can appear also after a long time from the implantation. 
Even if various tools are available for nonsurgical rejuvenation of the face, until recent years, cosmetic lipolytic injectables were lacking. Since 2015 in USA and Canada and 2 years later in parts of Europe as Italy, Poland and Check Republic, a dehoxycholic acid-based product has been available. The product is used according to a specific injection protocol, which includes a grid specifying proper placement. After dehoxycholic acid (DCA) injections, a various degree of swelling, redness and bruising of the injected area could be recorded [19]. Moreover, DCA injection could cause pain to the patient and this potential problem could be avoided by mixing DCA with lidocaine, effectively minimizing pain during injection.

In addition, patients suffering the stigmata of HIV infection can benefit of non-surgical aesthetic treatments performed with fillers or lipolytic agents $[18,19]$.

Office-based, minimally invasive aesthetic techniques are in high demand since they provide a quick and reliable service for facial rejuvenation with a low risk of complications and high patient satisfaction; however, as with any surgical procedure, complications can occur [20].

In the present paper, a retrospective analysis of complications following non-surgical aesthetic treatments in a cohort of 116 consecutive HIV+ patients, treated over a period of 12 years, was performed.

\section{Materials and Methods}

A retrospective evaluation of the complications related to cosmetic medical treatment performed on HIV+ patients presenting facial wasting or head and neck lipodystrophy, treated between January 2008 and December 2020, was performed. All the treatments were performed in private practices or in a public setting at the Maxillo-Facial Surgery Complex Unit of the Second University of Naples, renamed "Luigi Vanvitelli" University Hospital in 2016. The study was approved by the internal ethical committee of the University (AOU-SUN 167/2011). A total of 116 consecutive patients ( 21 females and 95 males), with ages ranging from 36 to 62 years old (mean 46.5 years old) were treated. Eligible criteria for inclusion: aged 18 and older, facial lipoatrophy, HIV-positive, patients receiving antiretroviral therapy, normal laboratory blood test examination performed at least 6 months earlier (serum chemistry, liver function tests, prothrombin time/partial thromboplastin time) with CD4 count at least $250 / \mathrm{mm}^{3}$ or greater, and a viral load lowers than 5000 copies $/ \mathrm{mL}$. Excluded from participation were patients already receiving facial injections of any other product. Other exclusion criteria were any active infections on the face, active treatment with interferon or systemic corticosteroids, pregnancy, breastfeeding, known preexisting renal disease and poorly controlled diabetes mellitus.

All 116 patients were concerned regarding facial lipoatrophy; four of them also presented head and neck lipohypetrophy (three with buffalo hump and one with bullfrog neck). Patients were scored with the James-Carruthers Facial Lipoatrophy Severity Scale [21] (Table 1): 16 patients were scored as 1, 23 patients were scored as 2, 48 were scored as 3, and 29 were scored as 4.

Table 1. James-Carruthers Facial Lipoatrophy Severity Scale. The four grades of HIV-associated facial lipoatrophy are explained in detail.

\begin{tabular}{cc}
\hline Grade & Description \\
\hline 1 & Mild and localized facial lipoatrophy \\
2 & Deeper and longer atrophy, with the facial muscles beginning to show through \\
3 & Atrophic area is even deeper and wider, with the muscle clearly showing through \\
4 & Lipoatrophy covers a wide area, extending up towards the eye sockets, and the \\
& facial skin lies directly on the muscle \\
\hline
\end{tabular}

One hundred sixteen consecutive HIV+ patients were treated in order to reduce and/or ameliorate head and neck stigmata of the infection. In order to solve facial wasting, 42 patients received polyacrylamide hydrogel filler injections (Figures 1-3), 53 patients received calcium hydroxyapatite (CaHA)-based fillers and 21 hyaluronic acid (HA) fillers, 
four patients also received dehoxycholic acid (DCA) injections to reduce buffalo hump in three cases and submental fullness (bullfrog neck) in one more case.

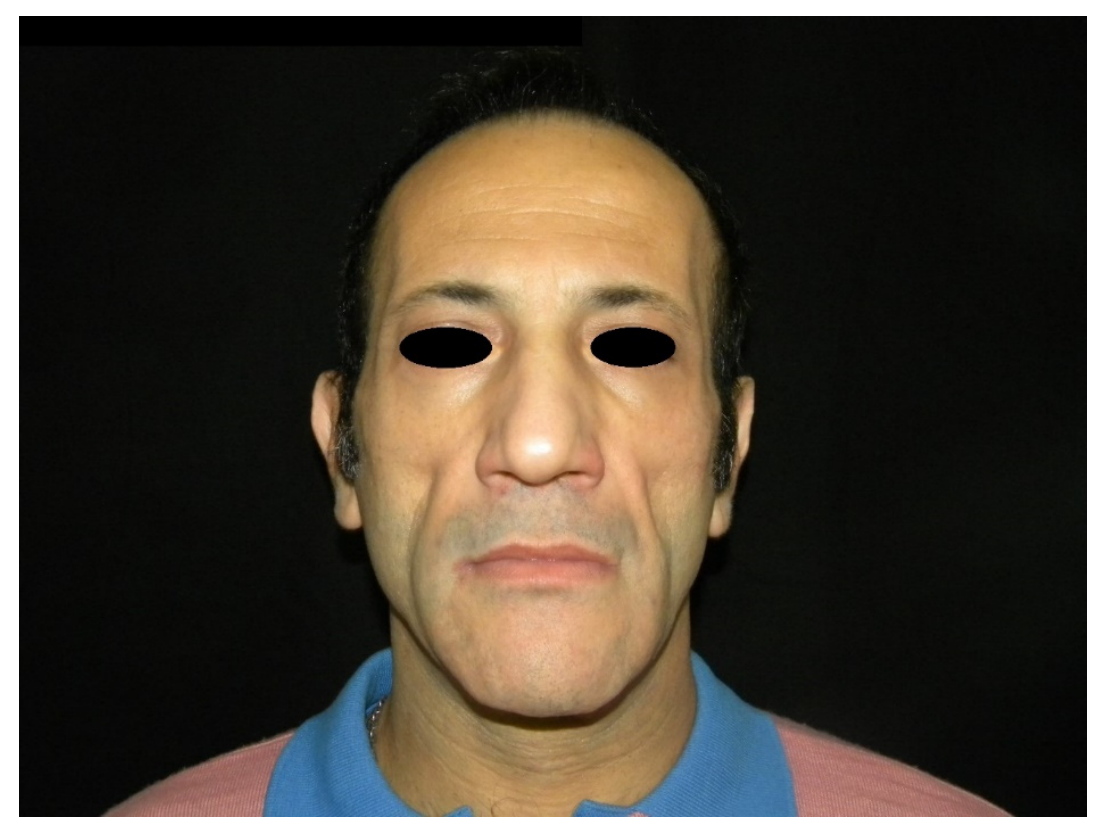

Figure 1. Preoperative frontal view of a patient presenting facial lipoatrophy.

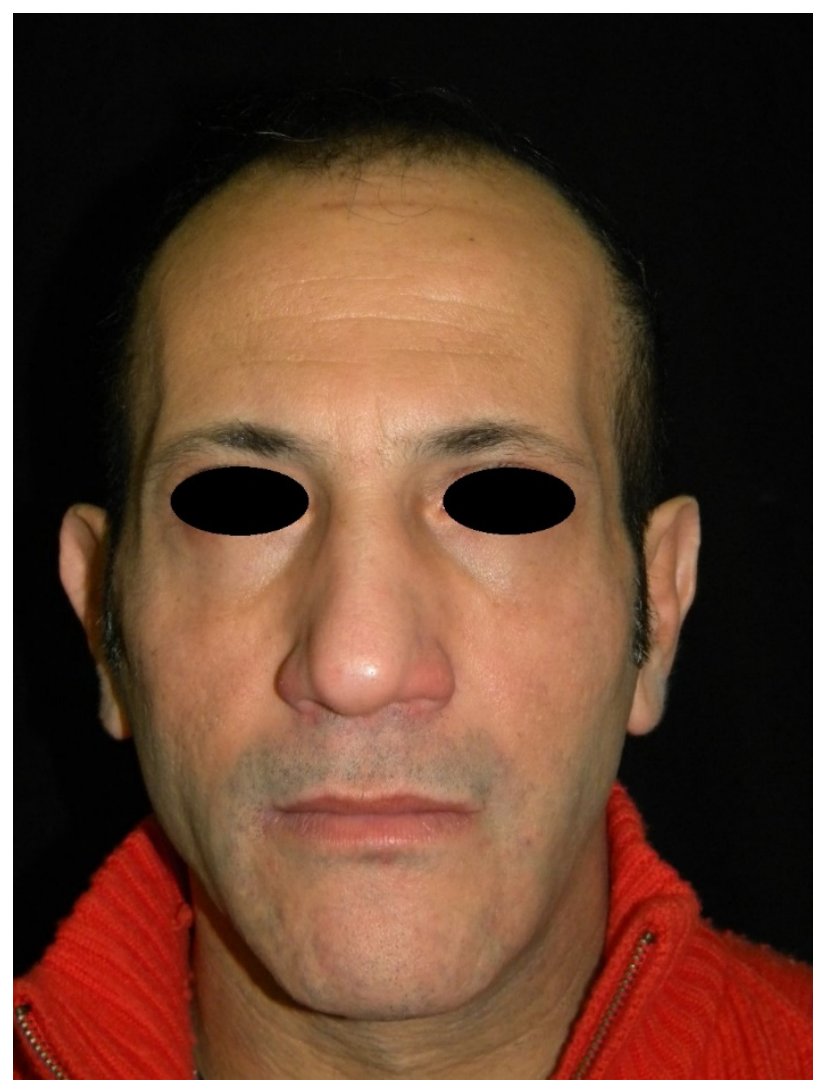

Figure 2. Frontal view of a patient presenting facial wasting (the same patient shown in Figure 1) treated with polyacrylamide hydrogel filler, at 6 months follow-up. 


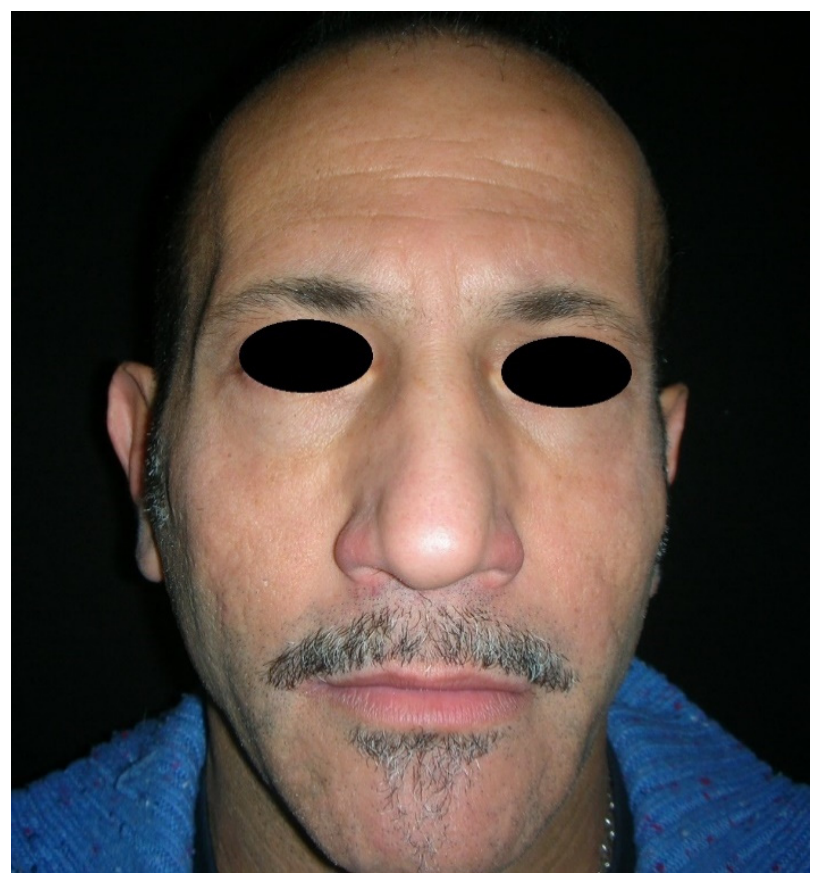

Figure 3. Frontal view of a patient presenting facial wasting (the same patient shown in Figure 1) treated with polyacrylamide hydrogel filler, at 2 years follow-up.

Facial rehabilitation was performed in one or more sessions of injections; each patient received the amount of product needed for full rehabilitation according to the patient's wishes in one or more sessions. Patients injected with polyacrylamide hydrogel were rehabilitated in 2.4 sessions on average. When CaHA or HA were injected, a lower number of session were recorded-1.3 and 1.1 sessions on average, respectively. Most of the patients injected with polyacrylamide hydrogel or CaHA fillers received a first "mega filling session" [22,23].

The main focus of the filler injections was to restore facial wasting, in order to improve this HIV-related stigmata. A triangular area of the face, previously described by Rauso et al., between the anterior margin of masseter muscle, the naso-labial fold and the malar area was injected as a focus and surrounding tissues were faded [24-26].

Patients receiving CaHA or HA fillers were re-injected after 8 to 12 months due to the transient effect of the medical device used. CaHA and HA filler injections were repeated at the University Hospital for 2 years; later, the use of these medical devices was stopped and they were not supplied anymore (in Italy all the procedures performed by the National Health Service are free of charge for patients). When these procedures were performed in private practices, filler injections were repeated for as long as patients were willing to receive them (most of them interrupted the injections for economic reasons).

Prophylactic antibiotic therapy was administrated and a previously-described aseptic protocol was applied only when a permanent filler (polyacrylamide hydrogel) was used [20]. DCA injections were performed in three patients injected with polyacrylamide hydrogel and one with calcium hydroxyapatite (Figures 4-6); DCA injections were performed separately from filler injections, at least 30 months apart from an injection session. Prophylactic antibiotic therapy was never administered when DCA was injected. Only 1 session of DCA injection was performed per each patient. 


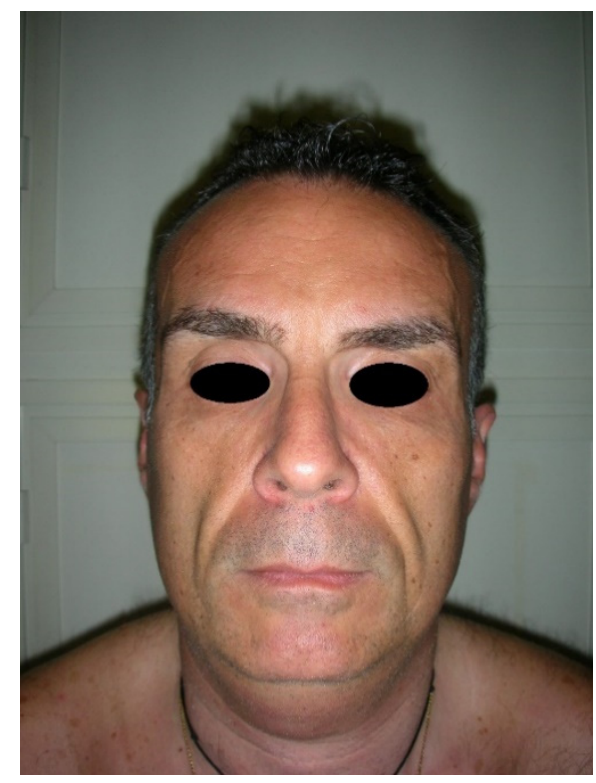

Figure 4. Preoperative frontal view of a patient presenting facial wasting and submental fullness.

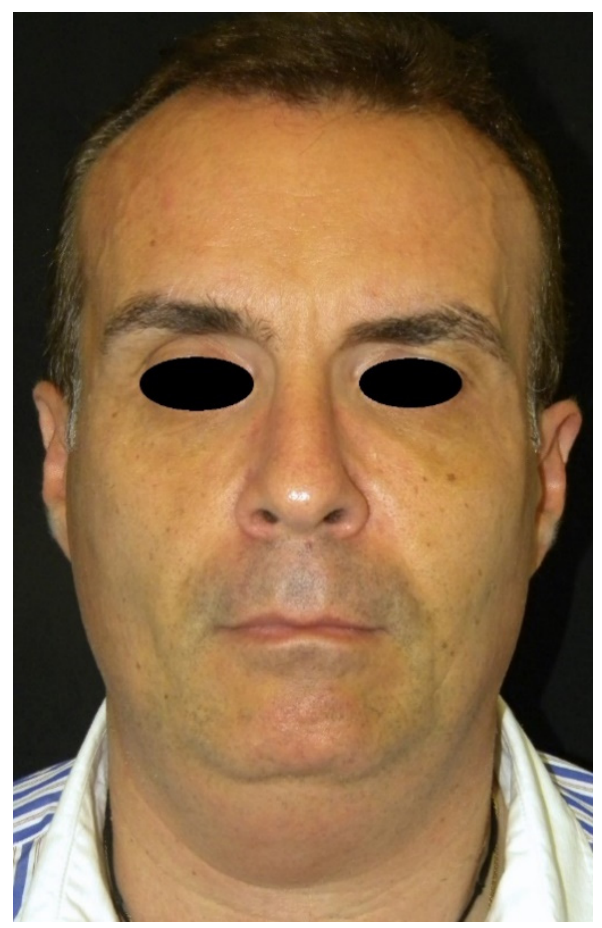

Figure 5. Frontal view of a patient presenting facial wasting and submental fullness (the same patient shown in Figure 4) treated with CaHA injection, at 3 months follow-up.

A total of 286 sessions of filler injections were performed between 2008 and 2020 in this patient population.

Follow-up ranged between 6 months and 9 years; follow up in patients receiving HA, CaHA and DCA was shorter compared to those injected with polyacrylamide hydrogel, respectively 1.2 years and 2.8 years on average. 


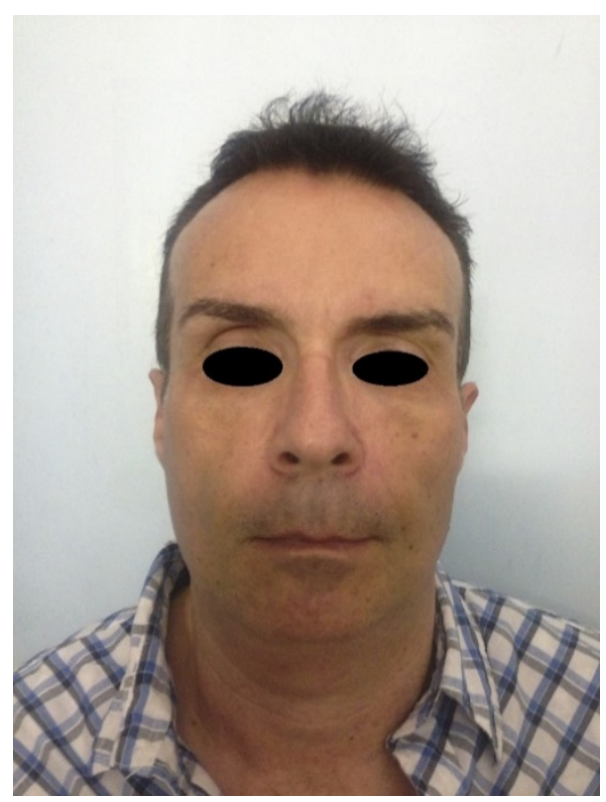

Figure 6. Frontal view of a patient presenting facial wasting and submental fullness (the same patient shown in Figure 4) treated with CaHA and DCA injection, at 8 months and 3 months follow-up respectively.

\section{Results}

Bruising, redness and a variable grade of swelling were transient records in all the patients receiving filler injection and these self-resolved within 2 to 7 days. After DCA injections, a huge degree of swelling, redness and bruising of the injected area was recorded for a time between 15 and 24 days (Figure 7).

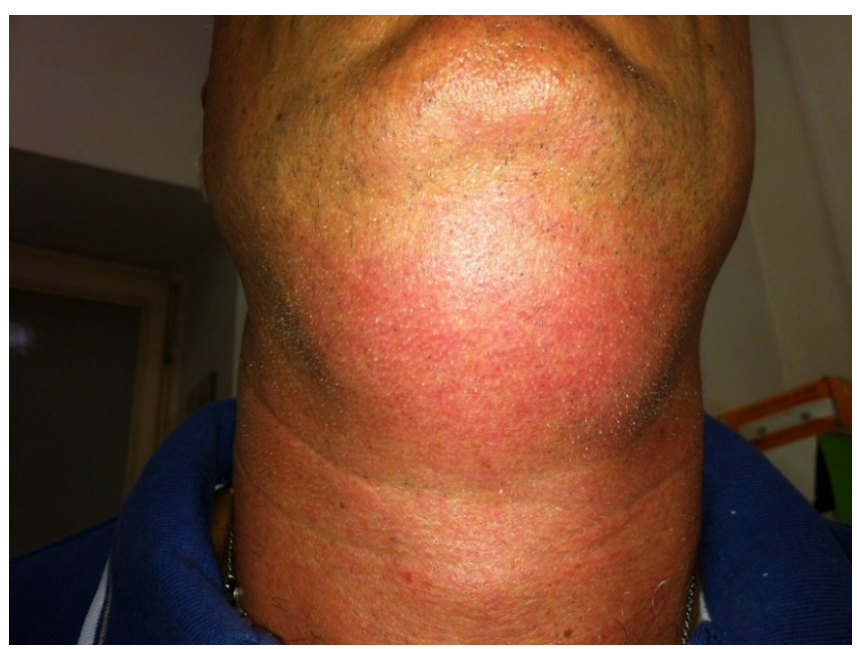

Figure 7. A huge degree of swelling, redness and bruising after DCA injections.

Patients receiving HA and DCA injections did not experience other complications. In a patient receiving CaHA, tardive huge swelling developed 3 weeks after the injections and the clinical situation was resolved after 3 days of oral corticosteroid therapy. Patients receiving polyacrylamide hydrogel injections showed small, palpable, nonvisible nodules in 13 cases in the first 5 years of follow up; after that period, most of the patients were lost for follow up. Two patients experienced gel induration after 8 years: one of them developed an aseptic abscess requiring drainage (Table 2). One more patient developed a huge abscess requiring surgical drainage 10 years after the injections (Figures 8-10). 
Table 2. Incidence and percentage of complications related to cosmetic medical treatment performed on HIV+ patients presenting facial wasting or head and neck lipodystrophy.

\begin{tabular}{cccccc}
\hline & \multicolumn{2}{c}{$\begin{array}{c}\text { Transient Bruising, } \\
\text { Redness, } \\
\text { Swelling }\end{array}$} & $\begin{array}{c}\text { Tardive Onset } \\
\text { Swelling }\end{array}$ & Nodules & Late Onset Abscess \\
\cline { 2 - 6 } & $\begin{array}{c}\text { Resolved } \\
\text { within 2-7 Days }\end{array}$ & $\begin{array}{c}\text { Resolved within } \\
\text { 15-24 Days }\end{array}$ & & & $0(0 \%)$ \\
\hline HA & $116(100 \%)$ & $0(0 \%)$ & $0(0 \%)$ & $0(0 \%)$ & $0(0 \%)$ \\
\hline DC & $0(0 \%)$ & $1(1.2 \%)$ & $1(1.2 \%)$ & $0(0 \%)$ & $0(0 \%)$ \\
\hline CaHA & $116(100 \%)$ & $0(0 \%)$ & $0(0 \%)$ & $13(15 \%)$ & $3(3.5 \%)$ \\
\hline Polyacrylamide & $116(100 \%)$ & $0(0 \%)$ & & & 0 \\
\hline
\end{tabular}

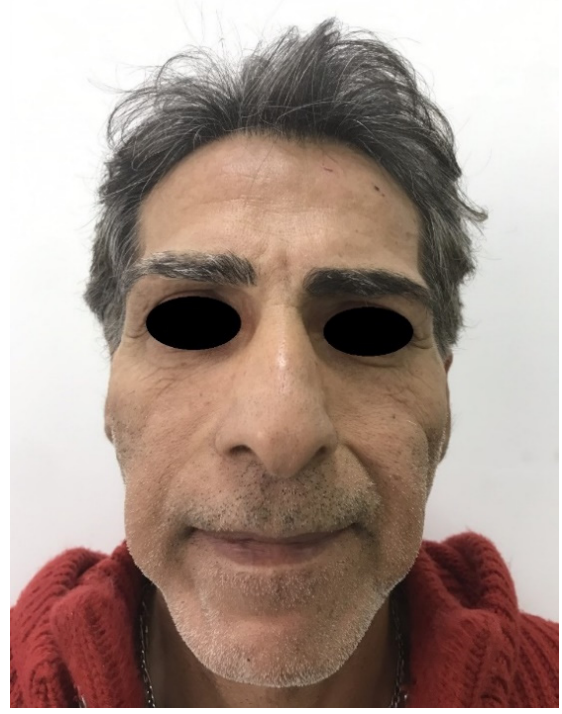

Figure 8. Bilateral huge abscess in a patient receiving polyacrylamide hydrogel injections 10 years after treatment.

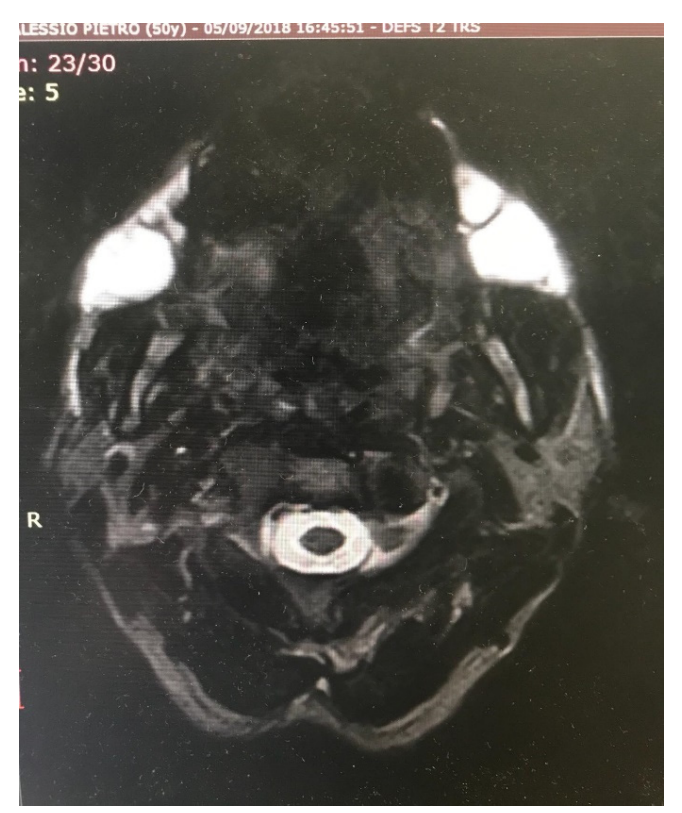

Figure 9. Magnetic Resonance Imaging (MRI) of bilateral huge abscess in a patient (the same patient shown in Figure 8) receiving polyacrylamide hydrogel injections 10 years after the treatment. 


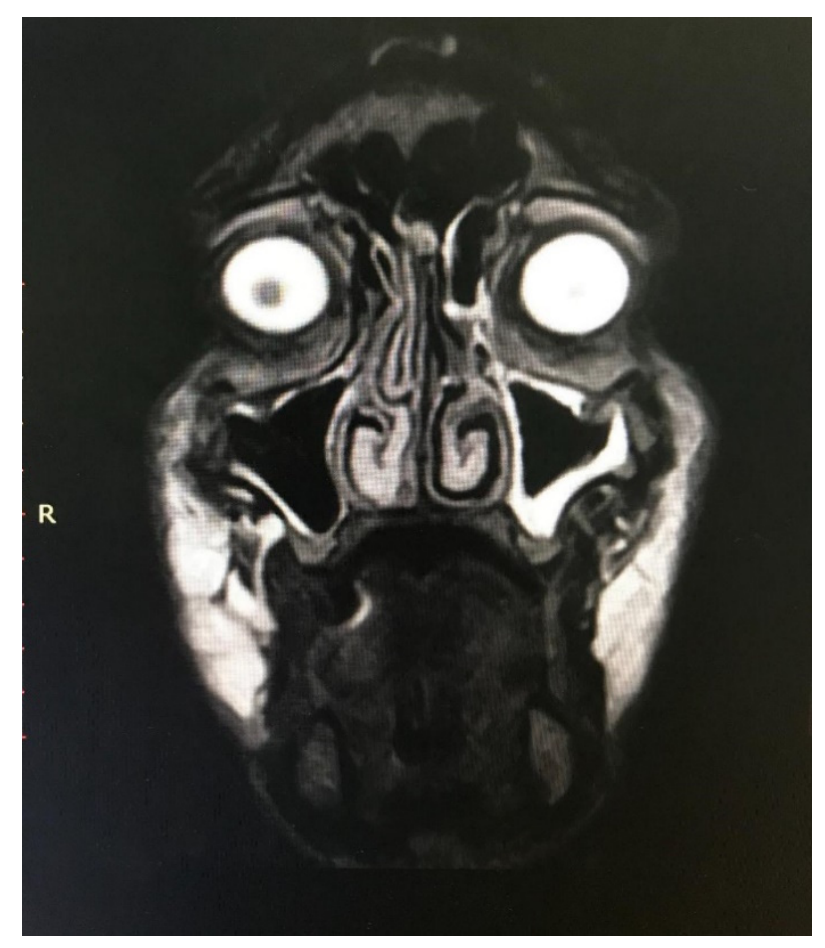

Figure 10. MRI of Caucasian male patient from Figure 8 showing bilateral collection of semifluid material. veloped.

Only these three patients were followed up for 9 years, due to the complications de-

\section{Discussion}

The use of highly-active retroviral therapy (HAART) with protease inhibitors, first described in the United States in 1997, has demonstrated a significant clinical benefit in the treatment of HIV infection [1,2]. Within one year of its introduction, mortality rates dropped by $45 \%$ and there was a significant decline in the number of reported AIDSdefining diseases. However, as in most chronic pharmacological therapies, there are several side effects, such as diarrhea, renal calculi, nausea and perioral paraesthesia $[3,4]$.

One medication-associated condition that has become prevalent among HIV-infected patients is HIV-associated lipodystrophy, a syndrome characterized by abnormal fat metabolism and deposition. Broadly speaking, lipodystrophy syndrome is composed of three components: lipoatrophy (subcutaneous fat loss in the face, limbs and buttocks), lipohypertrophy (fat accumulation in the abdomen, dorso-cervical or cervical fat pads) and metabolic disturbance (insulin resistance, hypercholesterolemia and hypertriglyceridemia) [6].

Facial lipoatrophy, also known as facial wasting, is the most distressing manifestation for HIV patients. It can be stigmatizing, severely affecting quality of life and self-esteem, and it may result in reduced antiretroviral adherence [5].

A number of medical, pharmacological, and surgical therapies are used to treat HIV lipodystrophy. In addition to physical exercise and nutritional counselling to prevent the loss of lean body mass, anabolic steroid hormones, testosterone and human growth hormone have increasingly been used in these patients, with varied success and significant side effects [6]. Therefore, ever-increasing numbers of HIV patients receiving HAART are presenting to aesthetic physicians requesting non-surgical procedure to ameliorate the unwanted side effects of their treatment protocol such as facial wasting and buffalo hump.

As stated by De Santis et al., HIV+ patients are considered a very high-risk group in terms of susceptibility to infections $[27,28]$ : probably due to this reasons, physicians are often afraid to treat this patient population. 
However medical literature shows that facial fillers are a reasonable option when facial lipoatrophy is the only stigmata of lipodystrophy; Sturm et al. performed a systematic review to determine the safety and efficacy of permanent and semipermanent dermal fillers to treat the visible effects of HIV-associated facial lipoatrophy [18]. They affirmed that the small number of well-designed studies limited the ability to draw firm conclusions; however, polylactic acid and polyacrylamide gel were the dermal fillers most used and the studies cited by the authors showed that these fillers do not tend to cause serious short-term adverse events [18].

In the present retrospective study, the authors investigated the complication rates of non-surgical aesthetic procedures in HIV+ patients in a long-range period, from 2008 to 2020. In the paper released by Levy and Emer regarding the complications of minimally invasive cosmetic procedures (considering non-infected patients), bruising, erythema and pain were found to be the most common complications with injectables [20]. In the present cohort of patients the most common transient and self-resolved complications were also bruising and redness. Infection was never observed with HA and CaHA fillers; in patients treated with polyacrylamide hydrogel, early complications were similar to those of HA and CaHA, with the exception of small palpable non-visible nodules in 13 patients over 42 $(30.9 \%)$, which persisted at 5 years follow-up. Three cases of late-onset complications, one gel induration and two abscesses were also recorded (7.1\%).

In the medical literature, the use of polyacrylamide hydrogel filler has shown contrasting results. Pallua and Walter, in a prospective multi-center study of 251 patients, with a 5-year assessment of safety and aesthetic results after facial soft-tissue augmentation with polyacrylamide hydrogel, recorded a total of 53 adverse events and two serious adverse events related to treatment, thirteen adverse events which were gel indurations and four cases of infection [29]. On the other hand, Manafi et al. published a series of unacceptable results following polyacrylamide hydrogel injections: the study evaluated 98 patients who attained unsatisfactory results and complications from injections with Aquamid. The most common adverse events seen were inflammation (52\%), asymmetry (32\%), irregularity $(18 \%)$, abscess formation and infection (11\%) and product displacement (8\%) [30].

Nevertheless, short-, medium- and long-term encouraging results have been published over time, leading us to consider polyacrylamide hydrogel filler a good and safe option in facial wasting rehabilitation [26-28,31-33]. In 2015, Negredo et al. presented their 10-year experience with 751 patients, recording indurations in $6.7 \%$ of patients and nodules in $3.8 \%$. Five patients (4.8\%) had local infections. A further 15 patients with a shorter follow-up (less than 10 years) presented local infections (overall incidence of infection 2.7\%); the product had to be withdrawn in three cases [32].

Regarding the tardive swelling that developed in one patient receiving CaHA filler injections, this was already published by Rauso as an anomalous case report [34], although it was resolved with 3 days of oral corticosteroids; an acute inflammation of the injected fillers, as recently described for HA fillers, was hypothesized [35].

In the present paper, four patients also received DCA injections in order to reduce buffalo hump in three cases and bullfrog neck in another one. The buffalo hump deformity is a well-described manifestation of HIV-associated lipodystrophy, characterized by dorsocervical fat pad enlargement [19]. The bullfrog neck deformity is a much rarer clinical condition and is represented by a different degree of cervical fat pad enlargements [36]. After DCA injections, a huge degree of swelling, redness and bruising of the injected area was recorded for a period between 15 and 24 days, and no other complications were recorded. Immediate post-operative swelling, pain and redness lasting 15 to 28 post injective days is the normal course following DCA injections. When DCA is injected into fat, it alters the permeability of fat cell membranes, causing progressive cellular swelling that ultimately results in the breakup of fat cells. This process can take several days to several weeks. After the cellular breakup, macrophages enter the site and eliminate the cytoplasm and cell membrane, while the healing process is carried out through the development of fibrotic tissue. The entire process, including healing, usually takes several months $[37,38]$. 
With the exception of the tardive swelling reported after CaHA injections, complications were recorded just after polyacrylamide hydrogel injections and are coherent with what already published in literature.

The main limitation of the present study in represented by the lack of continuous follow-up for all of the patients.

Although the patients' satisfaction is beyond the topic of this article, all the patients were happy or very happy with the results. However, when late-onset complications arose, in the two patients who required abscess drainage, their compliance dramatically decreased [39].

\section{Conclusions}

$\mathrm{HIV}+$ patients receiving antiretroviral therapy may develop alterations of the head and neck area, mainly represented by facial wasting and cervical and dorso-cervical fat pad enlargement. This patient population can benefit from non-surgical aesthetic procedures and the complication rate seems to be comparable to that of non-infected patients. To confirm this statement, further randomized, blinded studies need to be performed.

Author Contributions: Conceptualization, G.M.R.; methodology, G.T.; validation, R.F., G.L.G. and L.P.; formal analysis, N.D.F.; investigation, A.C.; resources, L.R.; data curation, N.S.; writing-original draft preparation, F.C.; writing—review and editing, G.M.R.; visualization, G.T., R.F., G.L.G. and L.P.; supervision, N.D.F., A.C. and L.R.; project administration, N.S. and F.C. All authors have read and agreed to the published version of the manuscript.

Funding: This research received no external funding.

Institutional Review Board Statement: All procedures performed in studies involving human participants were in accordance with the ethical standards of the institutional and national research committee and with the 1964 Helsinki declaration and its later amendments or comparable ethical standards.

Informed Consent Statement: Informed consent was obtained from all subjects involved in the study. Written informed consent has been obtained from the patients to publish this paper if applicable.

Data Availability Statement: Not Applicable.

Conflicts of Interest: The authors declare no conflict of interest.

\section{References}

1. Danner, S.A.; Carr, A.; Leonard, J.M.; Lehman, L.M.; Gudiol, F.; Gonzales, J.; Raventos, A.; Rubio, R.; Bouza, E.; Pintado, V.; et al. A short-term study of the safety, pharmacokinetics, and efficacy of ritonavir, an in-hibitor of HIV-1 protease. European-Australian Collaborative Ritonavir Study Group. N. Engl. J. Med. 1995, 333, 1528-1533. [CrossRef] [PubMed]

2. Hammer, S.M.; Squires, K.E.; Hughes, M.D.; Grimes, J.M.; Demeter, L.M.; Currier, J.S.; Eron, J.J., Jr.; Feinberg, J.E.; Balfour, H.H., Jr.; Deyton, L.R.; et al. A controlled trial of two nucleoside analogues plus indinavir in persons with human immunodeficiency virus infection and CD4 cell counts of 200 per cubic millimetre or less. AIDS Clinical Trials Group 320 Study Team. N. Engl. J. Med. 1997, 337, 725-733. [CrossRef] [PubMed]

3. Lichtenstein, K.A. Redefining lipodystrophy syndrome: Risks and impact on clinical decision making. J. Acquir. Immune Defic. Syndr. 2005, 39, 395-400. [CrossRef] [PubMed]

4. Carr, A.; Samaras, K.; Burton, S.; Law, M.; Freund, J.; Chisholm, D.J.; Cooper, D.A. A syndrome of peripheral lipodystrophy, hyperlipidaemia and insulin resistance in pa-tients receiving HIV protease inhibitors. AIDS 1998, 12, F51-F58. [CrossRef] [PubMed]

5. Duran, S.; Savès, M.; Spire, B.; Cailleton, V.; Sobel, A.; Carrieri, P.; Salmon, D.; Moatti, J.-P.; Leport, C. Failure to maintain long-term adherence to highly active antiretroviral therapy: The role of lipodystrophy. AIDS 2001, 15, 2441-2444. [CrossRef]

6. Davison, S.P.; Timpone, J.; Hannan, C.M. Surgical Algorithm for Management of HIV Lipodystrophy. Plast. Reconstr. Surg. 2007, 120, 1843-1858. [CrossRef]

7. Scorza, A.R.; Scorza, L.R.; Troccola, A.; Micci, D.M.; Rauso, R.; Curinga, G. Autologous fat transfer for face rejuvenation with tumescent tech-nique fat harvesting and saline washing: A report of 215 cases. Dermatology 2012, 224, 244-250. [CrossRef] [PubMed]

8. Portincasa, A.; Trecca, E.M.C.; Ciancio, F.; Annacontini, L.; Bufo, P.; Fortunato, F.; Cecchino, L.; Parisi, D.; Cassano, M. The role of lipofilling in reconstructions with dermal regeneration template: Clinical and histological assessment. J. Biol. Regul. Homeost. Agents 2018, 32, 171-176. 
9. Rauso, R.; Curinga, G.; Santillo, V.; Corvo, G.; Tartaro, G. Comparison between lipofilling and a non resorbable filler for facial wasting rehabil-itation in HIV+ patients. J. Craniofac. Surg. 2011, 22, 1684-1688. [CrossRef]

10. Rauso, R.; Gherardini, G.; Greco, M.; Tartaro, G. Is buffalo hump fat the perfect filler for facial wasting rehabilitation? Reflection on three cases. Eur. J. Plast. Surg. 2012, 35, 553-556. [CrossRef]

11. American Society for Aesthetic Plastic Surgery: Cosmetic Surgery National Data Bank Statistics for 2016. Available online: https://www.surgery.org/sites/default/ files/ASAPS-Stats2016-11-12.pdf (accessed on 20 January 2021).

12. França Wanick, F.B.; Almeida Issa, M.C.; Luiz, R.R.; Soares Filho, P.J.; Olej, B. Skin Remodeling Using Hyaluronic Acid Filler Injections in Photo-Aged Faces. Dermatol Surg 2016, 42, 352-359. [CrossRef] [PubMed]

13. Scarano, A.; Sbarbati, A.; Amore, R.; Iorio, E.L.; Ferraro, G.; Marchetti, M.; Amuso, D. The role of hyaluronic acid and amino acid against the aging of the human skin: A clinical and histological study. J. Cosmet. Dermatol. 2020. [CrossRef] [PubMed]

14. Rauso, R.; Tartaro, G.; Chirico, F.; Zerbinati, N.; Albani, G.; Rugge, L. Rhinofilling with hyaluronic acid thought as a cartilage graft. J. Craniomaxillofac. Surg. 2020, 48, 223-228. [CrossRef] [PubMed]

15. Mashiko, T.; Mori, H.; Kato, H.; Doi, K.; Kuno, S.; Kinoshita, K.; Kunimatsu, A.; Ohtomo, K.; Yoshimura, K. Semipermanent volumization by an absorbable filler: Onlay injection technique to the bone. Plast. Reconstr. Surg. Glob. Open 2013, 1, 4-14. [CrossRef]

16. Marmur, E.S.; Phelps, R.; Goldberg, D.J. Clinical, histologic, and electron microscopic findings after injection of a calcium hydroxylapatite filler. J. Cosmet. Laser Ther. 2004, 6, 223-226. [CrossRef]

17. Lemperle, G.; Morhenn, V.; Charrier, U. Human Histology and Persistence of Various Injectable Filler Substances for Soft Tissue Augmentation. Aesthetic Plast. Surg. 2020, 44, 1348-1360. [CrossRef]

18. Sturm, L.P.; Cooter, R.D.; Mutimer, K.L.; Graham, J.C.; Maddern, G.J. A Systematic Review of Permanent and Semipermanent Dermal Fillers for HIV-Associated Facial Lipoatrophy. AIDS Patient Care STDs 2009, 23, 699-714. [CrossRef]

19. Rauso, R.; Rusciani, A.; Curinga, G. An adipocitolitic aqueous micro-gelatinous solution for buffalo hump deformity reduction. J. Drugs Dermatol. 2014, 13, 1282-1284.

20. Emer, J.J.; Levy, L.L. Complications of minimally invasive cosmetic procedures: Prevention and management. J. Cutan. Aesthetic Surg. 2012, 5, 121-132. [CrossRef] [PubMed]

21. James, J.; Carruthers, A.; Carruthers, J. HIV-associated facial lipoatrophy. Dermatol. Surg. 2002, 28, 979-986. [PubMed]

22. Rauso, R.; Curinga, G.; Rusciani, A.; Colella, G.; Amore, R.; Tartaro, G. Safety and efficacy of one-step rehabilitation of human immunodeficiency virus-related facial lipoatrophy using an injectable calcium hydroxylapatite dermal filler. Dermatol. Surg. 2013, 39, 1887-1894. [CrossRef] [PubMed]

23. Rauso, R.; Gherardini, G.; Parlato, V.; Amore, R.; Tartaro, G. Polyacrylamide gel for facial wasting rehabilitation: How many milliliters per ses-sion? Aesthetic Plast. Surg. 2012, 36, 174-179. [CrossRef] [PubMed]

24. Rauso, R.; Tartaro, G.; Freda, N.; Rusciani, A.; Curinga, G. A facial marker in facial wasting rehabilitation. J. Drugs Dermatol. JDD 2012, 11, 202-208.

25. Rauso, R.; Tartaro, G.; Cobellis, G.; San Giovanni, V.; Colella, G. Human Immunodeficiency Virus-Related Lipoatrophy of the Face: Where Should We Have to Fill? Plast. Reconstr. Surg. 2011, 127, 143e-144e. [CrossRef]

26. Rauso, R. 5-Year Study of a Polyacrylamide Hydrogel-Based Filler for Rehabilitation of HIV-Related Facial Lipoatrophy. Aesthetic Surg. J. 2015, 35, 1021-1029. [CrossRef] [PubMed]

27. De Santis, G.; Jacob, V.; Baccarani, A.; Pedone, A.; Pinelli, M.; Spaggiari, A.; Guaraldi, G. Polyacrylamide hydrogel injection in the management of human immunodeficiency virus-related facial lipoatrophy: A 2-year clinical experience. Plast. Reconstr. Surg. 2008, 121, 644-653. [CrossRef]

28. De Santis, G.; Pignatti, M.; Baccarani, A.; Pedone, A.; Spaggiari, A.; Orlando, G.; Guaraldi, G. Long-term efficacy and safety of polyacrylamide hydrogel injection in the treatment of human immunodeficiency virus-related facial lipoatrophy: A 5-year follow-up. Plast. Reconstr. Surg. 2012, 129, 101-109. [CrossRef]

29. Pallua, N.; Wolter, T.P. A 5-year assessment of safety and aesthetic results after facial soft-tissue augmentation with polyacrylamide hydrogel (Aquamid): A prospective multicenter study of 251 patients. Plast. Reconstr. Surg. 2010, 125, 1797-1804. [CrossRef]

30. Manafi, A.; Emami, A.-H.; Pooli, A.H.; Habibi, M.; Saidian, L. Unacceptable Results with an Accepted Soft Tissue Filler: Polyacrylamide Hydrogel. Aesthetic Plast. Surg. 2009, 34, 413-422. [CrossRef]

31. Rauso, R.; Freda, N.; Parlato, V.; Gherardini, G.; Amore, R.; Tartaro, G. Polyacrylamide Gel Injection for Treatment of Human Immunodeficiency Virus-Associated Facial Lipoatrophy: 18 Months Follow-Up. Dermatol. Surg. 2011, 37, 1584-1589. [CrossRef]

32. Negredo, E.; Puig, J.; Aldea, D.; Medina, M.; Estany, C.; Perez-Alvarez, N.; Rodríguez-Fumaz, C.; Muñoz-Moreno, J.A.; Higueras, C.; Gonzalez-Mestre, V.; et al. Four-Year Safety with Polyacrylamide Hydrogel to Correct Antiretroviral-Related Facial Lipoatrophy. AIDS Res. Hum. Retrovir. 2009, 25, 451-455. [CrossRef] [PubMed]

33. Negredo, E.; Puig, J.; Ornelas, A.; Echeverría, P.; Bonjoch, A.; Estany, C.; Higueras, C.; Gonzalez-Mestre, V.; Clotet, B. Ten-Year Safety with Polyacrylamide Gel Used to Correct Facial Lipoatrophy in HIV-Infected Patients. AIDS Res. Hum. Retrovir. 2015, 31, 817-821. [CrossRef] [PubMed]

34. Rauso, R. A unique late complication with the use of calcium hydroxylapatite filler in facial lipoatrophy rehabilitation. Plast. Aesthetic Res. 2014, 1, 122. [CrossRef] 
35. Sadeghpour, M.; Quatrano, N.A.; Bonati, L.M.; Arndt, K.A.; Dover, J.S.; Kaminer, M.S. Delayed-Onset Nodules to Differentially Crosslinked Hyaluronic Acids: Comparative Incidence and Risk Assessment. Dermatol. Surg. 2019, 45, 1085-1094. [CrossRef] [PubMed]

36. Tierney, E.P.; Hanke, C.W. "Bullfrog neck," a unique morphologic trait in HIV lipodystrophy: Case series and review of the lit-erature. Arch. Dermatol. 2010, 146, 1279-1282. [CrossRef] [PubMed]

37. Rauso, R.; Tartaro, G.; Rugge, L.; Chirico, F.; Zerbinati, N. Remodeling the neck and the lower jaw with dehoxycholate injections. J. Biol. Regul. Homeost. Agents 2018, 32, 1279-1283.

38. Rauso, R.; Salti, G. A CE-Marked Drug Used for Localized Adiposity Reduction: A 4-Year Experience. Aesthetic Surg. J. 2015, 35, 850-857. [CrossRef]

39. Rauso, R.; Califano, L.; Rugge, L.; Chirico, F.; Tartaro, G. Late Onset Complications Secondary to Polyacrylamide Hydrogel-Based Filler for Re-habilitation of HIV-Related Facial Lipoatropy. Aesthetic Surg. J. 2018, 38, NP170-NP174. [CrossRef] 